\title{
Research on the Development of Agricultural Intellectual Property and the Strategies of Enriching in Rural China
}

\author{
Xue Zhang \\ School of Public Affairs, University of Science and Technology of China, Hefei, China \\ Email: Lena1125@mail.ustc.edu.cn
}

How to cite this paper: Zhang, X. (2019) Research on the Development of Agricultural Intellectual Property and the Strategies of Enriching in Rural China. American Journal of Industrial and Business Management, 9, 799-808.

https://doi.org/10.4236/ajibm.2019.94053

Received: February 24, 2019

Accepted: April 5, 2019

Published: April 8, 2019

Copyright $\odot 2019$ by author(s) and Scientific Research Publishing Inc. This work is licensed under the Creative Commons Attribution International License (CC BY 4.0).

http://creativecommons.org/licenses/by/4.0/

(c) (i) Open Access

\begin{abstract}
Agricultural intellectual property is the core force for the development of agricultural industry, and it is also an important part of the national strategies of strengthening the country. Based on the strategic background of the power of intellectual property, it is far-reaching for the development of agricultural intellectual property to be closely linked with the realization of rural prosperity. Strengthening the transformation of agricultural scientific and technological achievements and improving the core competitiveness of agriculture are important guarantees for the benefit of peasants. In view of the status quo of agricultural intellectual property development in our country, the paper analyzes the existing problems and the challenges faced in the transformation of agricultural scientific and technological achievements and it also proposes some practical strategies to realize the enrichment of the rural areas by agricultural intellectual property, which will provide some theoretical guidance for the early realization of IPR-based agriculture to benefit the farmers.
\end{abstract}

\section{Keywords}

Agricultural Intellectual Property, Enriching Rural People, Countermeasures

\section{Introduction}

As the fast development of economy and technology, the knowledge has become the important driving force for the development of industrial and agriculture. According to the innovation driving development strategy implemented by the state, building an innovative country is one of the most important tasks of China's economic construction. Intellectual property (IP) is an important force driven by innovation, therefore, IP as a symbol of the country's core competitive- 
ness is also receiving increasing attention.

In the past few decades, the state has promulgated the Outline of Medium and Long-term Science and Technology Development Plan, Outline of National Intellectual Property Strategy and Twelfth Five-Year Plan for National Intellectual Property Development to promote knowledge and independent innovation of property rights. At the end of 2015, the In-depth Implementation of the National Intellectual Property Strategy Action Plan (2014-2020) jointly issued by the State Intellectual Property Office and 27 ministries and commissions of the General Office of the State Council clearly put forward the new goal of building a strong intellectual property country. In addition, the policy documents related to Made in China 2025 and Public Entrepreneurship and Innovation issued by the State Council also deploy intellectual property as an important content. In 2016, Mr. Shen, director of the State Intellectual Property Office, said that the Thirteenth Five-Year Plan period is a major strategic opportunity for China's development and a key period for promoting the construction of an intellectual property country. To do a good job in this period and build a well-off society in an all-round way are significant.

In the report of the 19th National Congress, president Xi emphasized that accelerating the construction of an innovative country, advocating innovation culture, strengthening the creation, protection and application of intellectual property rights, and cultivating a large number of strategic scientific and technological talents, technological leaders, and young scientific and technological talents with international standards are most important. From what, it can be seen that the innovation driving approach with IP as the main content will be an important way to drive the overall development of China's economy.

Poverty is a problem that exists worldwide in every developing stages, therefore, poverty alleviation is also the typical issue of the times. China is a big agricultural country, according to the National Bureau of Statistics, as of 2012, China's rural population reached 970 million. Therefore, it is very important to improve the living standard of rural population. At present, the world's agriculture is developing in the direction of clean, high-tech and intelligent and under the strategic background of the one Belt and Road, China's agriculture is facing both opportunities and great challenges.

Accelerating the transformation of agricultural scientific and technological achievements and realizing the development of agricultural IP industrialization are much more important for developing of the country. In June 2010, the Ministry of Agriculture promulgated the Agricultural Intellectual Property Strategy Outline (2010-2020) and it clearly raised the agricultural IP strategy to a national position, especially after the 19th National Congress. Under the background of the era of IP strategy, it is more important and urgent to strengthen the management of agricultural IPRs, promote the transformation of agricultural scientific and technological achievements, increase the added value of agricultural production, to benefit the majority of farmers, and achieve poverty eradication. 


\section{Conception and Main Forms of Agricultural IP}

In 1967, the World Intellectual Property Organization (WIPO) formally proposed the concept of intellectual property. Since then, the term intellectual property has been recognized, translated and adopted by international organizations as a universal term. In China, intellectual property rights (IPRs) as a legal term first appeared in the General Principles of the Civil Law of the People's Republic of China adopted at the Fourth Session of the Sixth National People's Congress on April 12, 1986. IP refers to the exclusive rights that people owned in accordance with the law in their intellectual work. Usually, the state gives the creator exclusive rights to their intellectual achievements for a certain period. IPRs mainly include patent rights, trademark rights, copyrights, and exclusive rights to layout designs of integrated circuits, new varieties of plants, suppression of unfair competition, manufacturer names, and appellations of origin, source marks, and commerce secrets. At the same time, IPRs related to agriculture, namely agricultural IPRs, are defined as general names of the various rights that creators should owned according to the law in the agricultural and agricultural-related fields [1], and Agricultural-related IPRs include patents (inventions, utility models, designs), trademarks (collective marks, certification marks), geographical indications, new plant varieties, copyrights, trade secrets, technical secrets, genetic resources, traditional knowledge, and folk culture.

The Outline promulgated in March 2011, is the first programmatic document issued for the development status and actual development needs of China's agricultural IPRs, and a relatively complete distinction and generalization of agricultural IPRs. The Outline aims to enhance the ability to create, use, protect and manage agricultural IPRs, such as, agricultural plant variety rights, agricultural products geographical indications, agriculture-related patents, trademarks, copyrights, etc., and it also aims to strengthen technical support for agricultural development to ensure national food security, promote the sustainable and healthy development of agriculture. According to this outline, the main forms of agricultural IPRs are agricultural patent rights, new plant variety rights, agricultural trademark rights, agricultural trade secrets, and agricultural copyrights, of which, new varieties are the most important one.

According to the Patent Law of the People's Republic of China, the invention and improvement of agricultural machinery and tools in the field of agricultural science and technology can apply for invention or use of new patents; new technologies are for planting and aquaculture, fertilizer and feed formulations, and combinations of pesticides and veterinary drugs. The brewing technology of food, beverage and condiment can apply for invention patents; new microbial strains and products and methods for breeding new varieties of animals and plants can apply for invention patents. New varieties of agricultural plants include new varieties of plants such as grain, cotton, oilseeds, hemp, sugar, vegetables, tobacco, mulberry, tea, fruit, ornamental, grass, green manure, herbal medicine, edible fungi, algae and rubber trees. New plant varieties are not suitable for 
patent law protection, except for the United States and most countries in the world do not include plant varieties in the scope of patent protection. China's patent law also stipulates that new plant varieties cannot be granted patent rights. The agricultural trademark right, except for the exclusive right of the registered trademark owner to its registered trademark, the protection of the geographical indication right or the origin of the geographical name of the famous, excellent, special and rare agricultural products are generally also protected by the agricultural trademark category. Agricultural trade secrets refer to technical information that is not known to the public, can bring economic benefits to agricultural research institutions.

\section{Status of Agricultural IP Industrialization}

\subsection{Current Status of Agricultural IP Development in China}

The China Agricultural Intellectual Property Creation Index Report (2017) (as Report) released in 2017 systematically measured China's agricultural IP creation index, agricultural IP intensity, and agricultural knowledge such as variety rights and agricultural patents and it shows the quantitative trend, quality status, geographical distribution, industry composition, hotspots and superior units of property rights application and authorization. The Report is the most authoritative, complete and detailed statistical report on agricultural IPRs in China, and can comprehensively and specifically reflect the current detailed situation of China's agricultural IP development. According to the data of the Report. in 2016, the national agricultural IP creation index was $119.54 \%$, of which the application volume index was $120.98 \%$, an increase of $20.98 \%$ over 2015 ; the authorization volume index was $118.95 \%$, an increase of $18.95 \%$ over 2015 ; The maintenance period index was $118.72 \%$, an increase of $18.72 \%$ over 2015 . The data fully indicates that the quantity and quality of agricultural IP in China are simultaneously increasing. However, according to the contents of the Report, among the types of agricultural IP applications, colleges and research units accounted for $51.29 \%$, while the enterprises just accounted for $43.42 \%$ [2]. Due to amounts of factors, some colleges and research institutes cannot convert agricultural IP into real products, and cannot promote the industrialization of agricultural IP. Agricultural copyrights, that is, are held by rights owners in their scientific and technological activities, engineering design drawings and descriptions.

\subsection{Status of Agricultural IP Industrialization in China}

According to the latest report data, the quantity and quality of agricultural IP in China are growing at the same time, but the transformation of independent scientific and technological achievements is not effective. Meanwhile, the contribution rate to the agricultural economy is low, and there is no systematic agricultural IP industrialization chain.

The agricultural technology market in China started late, the operation me- 
chanism is not perfect, and there is no scientific property rights evaluation system. The scientific and technological achievements of colleges and universities and research institutes in China are relatively low in marketization, resulting in poor use of agricultural IPRs and industrialization, which affects the application of patents to a certain extent and the enthusiasm and creativity of the researchers.

At present, there are many reasons for the low conversion rate of agricultural scientific and technological achievements in China. First, most research departments generally have a tendency to attach importance to research results, ignoring the transformation of results, resulting in fewer results that can be transformed and applied. Second, the transformation of agricultural science and technology achievements severely lacks of necessary capital investment, which results in many agricultural scientific and technological achievements incapable of being transformed into actual products due to lack of funds. Third, the scale of the majority of agricultural scientific and technological achievements is small, and the ability to transform and apply in production is weak. The degree of commercialization and marketization of agricultural scientific and technological achievements is not enough.

At the same time, in the agricultural scientific and technological achievements, in addition to the high degree of commodification of the materialized technological achievements with a small share, a large number of non-physical technical achievements and basic theoretical results are low in commercialization, and even cannot be commercialized. That is to say, the fact that the materialized scientific and technological achievements account for a small share of the total output can be transformed into actual products through the market, while a large number of scientific and technological achievements are difficult to enter the market and be transformed into real agricultural products [3].

\section{National Poverty Alleviation Policies and Agricultural IPRs to Enrich the People}

\subsection{National Poverty Alleviation Policy}

As early as 1994, the State Council formulated and promulgated the National Eighty-Seven Poverty Alleviation Plan, and planned to solve the problem of food and clothing for 80 million people in rural areas in the country within seven years. Until 2001, the goal of addressing food and clothing has been achieved. With the development of the national economy and the improvement of people's living standards, the problem of food and clothing is no longer the standard of poverty. Realizing rural economic development, driving farmers to generate income, and realizing rural surplus are the main goal of poverty alleviation work nowadays. In 2011, the Central Committee of the Communist Party of China and the State Council issued the China Rural Poverty Alleviation and Development Program (2011-2020) (hereinafter referred to as Poverty Alleviation and Development Outline). In the fourth special poverty alleviation, it emphasizes 
industrial poverty alleviation and gives full play to the ecological environment and nature of poverty-stricken areas. It is significant to use resource advantages, advanced and practical technologies and vigorously tourism to realize poverty alleviation.

It is urgent to guide and support enterprises to invest in poverty-stricken areas, and drive poor farmers to increase their income. In November 2013, president Xi made clear that the first priority in poverty alleviation during the inspection in Xiangxi. By January 2015, president Xi emphasized in depth the implementation of precision poverty alleviation in Yunnan, and then in November 2015, the CPC Central Committee and State Council fight against poverty and puts forward the basic strategy of precise poverty alleviation and accurate poverty alleviation. The important central exposition of incentive poverty alleviation and precision poverty alleviation has formed a systematic thinking from theory to practice, which is not only guiding China's poverty alleviation work. The important policy has laid the ideological foundation for China's poverty alleviation and the goal of building a well-off society in an all-round way. Regardless of precision poverty alleviation, the national poverty alleviation policy and poverty alleviation concept have made new changes in the new era background. Therefore, science and technology poverty alleviation and IP alleviation will be the core measures for poverty alleviation.

In the past 30 years, with the joint efforts of the people and the whole country, China's poverty alleviation work has achieved successful results and the poverty alleviation policy has been gradually improved, and poverty alleviation work has gradually become systematic.

However, the current poverty alleviation situation is still not optimistic. There are still many problems, especially the poverty alleviation work in remote rural areas cannot be carried out in depth. Until now, the distribution of poverty-stricken population in rural areas is much in the west areas where the economic development is backward, the ecological environment is fragile, and the natural disasters are frequent. The development of the rural economy must rely on the agricultural industry, however, due to geographical location, transportation and resource constraints, the economics of these areas developed particularly slowly, and the agricultural economic development cannot achieve the scientific and technological standard. The 14 contiguous destitute areas clearly listed in the Outline basically cover most of the poor areas and deep poverty groups in the country. The contiguous mountain areas are: Liupan Mountain Area, Qinba Mountain Area, Wuling Mountain Area, Wumeng Mountain Area, Guizhou-Guilin Rocky Desertification Area, West Yunnan Border Mountain Area, Daxing'anling Nanxun Mountain Area, Yanshan-Taihang Mountain Area, Luliang Mountain Area, Dabie Mountain Area, In the contiguous areas of Luojing Mountain and other areas, Tibet, the four provinces, and the southern Xinjiang, which have clearly implemented special policies, will be the main battlefield for poverty alleviation in the next few years. 


\subsection{IPRs to Enrich the People}

With the in-depth implementation of the national IP strategy, the development of IP industrialization, especially the development of agricultural IP industry, has become more urgent. IPRs and enrichment of the people will make full use of agricultural IPRs to promote the transformation of agricultural scientific and technological achievements, and promote rural wealth.

In view of the issue of poor rural economic development, it is especially necessary to integrate IP assistance into poverty alleviation in rural areas. The added value of economic growth created by the development of IP industrialization in agricultural industry will better achieve rural economic growth and farmers' income generation. The essence of IP enrichment is to make full use of agricultural IPRs, promote the transformation of agricultural scientific and technological achievements, improve the scientific and technological content of agricultural production, enhance the competitiveness of agricultural products market, and promote the economic development of agricultural industry, thus helping rural people to get rid of poverty and achieve prosperity.

\section{Countermeasures of Enriching the People with Agricultural IP}

Agricultural problems are the fundamental issues concerning the national economy and the people's livelihood. We must always address the issues of agriculture, rural areas and farmers as the top priority of the whole work. It must be adhered to the priority development of agriculture and rural areas, in accordance with industrial prosperity, ecological livability, and rural civilization. General requirements for effective governance and affluence are to establish and improve the policy system for the integration of urban and rural development, and accelerate the modernization of agriculture and rural areas.

\subsection{Priority to the Investment in Transformation of Agricultural Patents}

The agricultural science and technology achievements have a long cycle of transformation and the profits are of risks [4]. Therefore, the state should take the advantages of the system to give priority to support scientific and technology research and development in key agricultural technology areas, through project entrustment, financial support, and tax reduction.

It should take the opportunity of the Thirteenth Five-Year Plan for the management of central science and technology plans, giving full play to the role of special national science and technology projects and funds for science and technology projects, exploring and implementing the key projects demonstration of environmental science and technology, with a view to solve the bottleneck of energy resources in economic and social development, focusing on hot issues in the field of resources and environment, and prominent problems affecting people's production and life, integrating resources, and tackling key core tech- 
nologies in new energy, new materials, biomedicine, bio-agriculture, environmental governance, etc.

In the same time, research institutes related to agricultural science and technology achievements, should provide strong intellectual support for innovative research and development of enterprises.

\subsection{Establishing an Intelligent Agriculture Platform}

Agricultural Intellectual Platform is a public welfare for integrating agricultural IP related information, which aims to benefit farmers with agricultural IPRS and eliminate rural poverty.

At present, the domestic public welfare platform for agricultural IP research and information integration is established one after another, of which, the better is the Zhinong 361 platform, which was officially established by the Chinese Academy of Agricultural Sciences in June 2007. The Center is an academic institution of agricultural IP related issues composed of experts in related fields, which aims to promote discipline development, provide decision support, enhance international cooperation, strengthen personnel training, and promote information sharing through investigation and research, exchanges and cooperation, education and training. Regular academic conferences and training in agricultural intellectual property are held in the research center. To achieve poverty alleviation in rural areas, the platform related to agricultural IPRs for intellectual agriculture and farmers should be established extensively. Until now, the establishment of a smart agriculture platform by provinces and counties were no more than 2400 which are not enough. The classification of intellectual agricultural platforms integrates agricultural intellectual property information resources, which will be more conducive to the operation and management of agricultural IPRs, and more effectively achieve the transformation of agricultural scientific and technological achievements, thus realizing the national strategy of strengthening IPRs, developing agriculture, and enriching the people.

\subsection{Cultivating Professional Talents}

Training professional talents in agricultural IP management is an important guarantee for strengthening and fully realizing agricultural IP services. The report of the 19th National Congress of the Communist Party of China proposed to strengthen IP protection, enhance the scientific and technological competitiveness of the agricultural industry, and fully explain the importance of intellectual property protection. Of course, the protection of agricultural IPRs is more important and it also urgent to cultivate professional talents in agricultural IPRs, strengthen the protection of agricultural IPRs, and provide intellectual support for agricultural production. The professionals in agricultural IP management can more effectively realize the protection, operation and management. Thus, it is meaningful to provide talent guarantee for the transformation of agricultural scientific and technological achievements. The ultimate goal of 
agricultural IP management is to increase the scientific and technological content for agricultural products, thereby increasing the benefit of agricultural products for the farmers to escape from the poverty.

\subsection{Improving the Scientific and Cultural Quality of Farmers}

The promotion of IPRs in rural areas is of great significance. The purpose of strengthening IPR propaganda in rural agriculture is to strengthen farmers' awareness of using science and technology to engage in farming, and to change traditional agricultural production awareness, strengthen farmers' concept of using scientific producing methods, and increase the benefit and market competitiveness of agricultural products.

The era of agriculture 3.0 is a new trend in the development of agriculture in the world today, with the internet and modern science and technology as the main features [5]. To develop modern agriculture, we must equip agriculture with modern material conditions, transform agriculture with modern science and technology, upgrade agriculture with modern industrial systems, promote agriculture with modern management, lead agriculture with modern development concepts, develop agriculture with new farmers, and improve agriculture. The level of water conservancy, mechanization and information will increase land output rate, resource utilization rate and agricultural labor productivity, and improve agricultural quality, efficiency and competitiveness. The scientific awareness and scientific and cultural quality of farmers are not high, which hinders the farmers' effective demand for agricultural science and technology. The proportion of laborers with junior high school education and below is the majority of the rural labor force in China, while farmers are the main force of agricultural production. The scientific and cultural literacy has far-reaching significance for improving labor productivity. Thus, it is urgent to improve the quality of the farmers.

\section{Conclusions}

In the process of the development of world agricultural towards the agricultural 3.0 era, the agricultural development of China must enhance its market competitiveness, take science and technology as the guide, strengthen agricultural scientific and technological achievements, and raise agricultural IP awareness.

Based on the current development status of China's agricultural IPRs, in order to truly realize agricultural IPRs and benefit the people, it is necessary to extensively establish agricultural IP platform, strengthen the professional talent training of agricultural IP operation management, and promote rural agriculture. The introduction of IP knowledge provides technology and talent protection for rural agricultural production. Nowadays, China faces a series of problems in the process of agricultural scientific and technological achievements transformation and the operation of agricultural IPRs, involving agricultural IP social awareness, professional agricultural IP management talents, agricultural IP manage- 
ment and service system, etc. On the other hand, to solve these problems, we must find a way to adapt to the development status of China's own agriculture and the actual situation of agricultural IP operations.

The establishment of the intelligent agriculture platform, the cultivation of operational talents and the popularization of IP knowledge in rural agriculture are the countermeasures that can solve practical problems at present, which can link agricultural science and agricultural production, improve the scientific and technological content of agriculture, and promote the transformation of agricultural scientific and technological achievements. It is also meaningful to improve the competitiveness of agricultural products market, increase agricultural income, farmers' income, and finally realize the purpose of using agricultural IP to benefit farmers and eliminate rural poverty.

\section{Conflicts of Interest}

The author declares no conflicts of interest regarding the publication of this paper.

\section{References}

[1] Song, M. (2010) Agricultural Intellectual Property. China Agriculture Press, Beijing.

[2] Yang, X.J. and Fan, Z.M. (2017) Enlightenment of Agricultural Intellectual Property Service System in Developed Countries to China. Journal of Northwest A\&F University (Social Science Edition), 17, 136-143.

[3] Wang, J.H. and Zhong, C.Y. (2012) Accelerate Transformation of Agricultural Science and Technology to Promote Agricultural Development Mode. Research of Agricultural Modernization, 33, 195-198.

[4] Wang, S.J. and Li, C.X. (2005) Obstacle Analysis and Countermeasure of Transformation of Agricultural Scientific and Technological Achievements in China. Science \& Technology and Economy, 18, 27-29.

[5] Wan, B.R. (2014) Trends and Suggestions of Agricultural Development in China. Issues in Agricultural Economy, No. 4, 4-7. 